\title{
PENENTUAN ALLOWABLE SPAN ANTAR PENYANGGA PIPA SLF BERDASARKAN TEGANGAN, DEFLEKSI, FREKUENSI ALAMI
}

\author{
Pekik Mahardhika ${ }^{1}$ \\ ${ }^{1}$ Program Studi Teknik Perpipaan, Jurusan Teknik Permesinan Kapal \\ Politeknik Perkapalan Negeri Surabaya, Jl. Teknik Kimia Kampus ITS Surabaya, 60111 \\ email: pekikmahardhika@ppns.ac.id
}

\begin{abstract}
The lubricant Industry is rapidly growing industry Processing of lubricating oil industry there are 3 stages of process that is Pre-flash, Thermal de-asphalthing and Hydrofinishing. The hydrofinishing process is divided into 3 oil products namely Spindel Lube Fraction, High Lube Fraction, Light Lube Fraction. In the lubricant industry there is SLF (Spindel Lube Fraction). Spindel Lube Fraction piping system from pump to condenser. Weight of pipe and fluid is sustained load. Maximum allowable span between horizontal pipe supports is limited by 3 main factor, it is bending stress, vertical deflection, and natural requency. Research aims to determine of maximum allowable span between pipe supports by calculation based on limited of stress, deflection, and natural frequency. Maximum allowable span between pipe supports is 9,18 ft (2800 $\mathrm{mm}$ ) and the natural frequency of pipe is 14,41 cps. Number of support on Spindel Lube Fraction line is 11pieces of supports.
\end{abstract}

Key Words:Deflection, Lubricant Industry, Natural Frequency, Spindel Lube Fraction, Stress

\begin{abstract}
ABSTRAK
Industri minyak pelumas merupakan industri yang berkembang pesat. Proses pengolahan industri minyak pelumas ada 3 tahapan proses yaitu Pre-flash, Thermal de-asphalthing dan Hydrofinishing. Proses hydrofinishing dibagi menjadi 3 produk oli yaitu Spindel Lube Fraction, High Lube Fraction, Light Lube Fraction. Di industri minyak pelumas terdapat sistem perpipaan SLF (Spindel Lube Fraction). Spindel Lube Fraction dari pompa menuju kondensor. Pipa dan fluida memiliki berat sehingga memerlukan penyangga. Maksimum jarak yang diijinkan antara penyangga pipa dibatasi 3 faktor utama yaitu tegangan tekuk, defleksi vertikal, dan frekuensi alami. Pipa yang terhubung dengan pompa (Pulsation line) harus memiliki frekuensi alami lebih dari $8 \mathrm{cps}$. Penelitian bertujuan untuk menentukan maksimum jarak yang diijinkan penyangga pipa dengan perhitungan berdasarkan batasan tegangan, defleksi, dan frekuensi alami. Maksimum jarak yang diijinkan antara penyangga pipa sebesar $9,18 \mathrm{ft}(2800 \mathrm{~mm})$ dan pipa memiliki frekuensi alami sebesar 14,41 cps. Jumlah penyangga yang dibutuhkan pada jalur pipa Spindel Lube Fraction yaitu 11 buah penyangga.
\end{abstract}

Kata Kunci: Defleksi, Frekuensi Alami, Industri Minyak Pelumas, Spindel Lube Fraction, Tegangan

\section{PENDAHULUAN}

Industri minyak pelumas merupakan industri yang berkembang pesat pada saat ini. Proses pengolahan industri minyak pelumas ada 3 tahapan proses yaitu Pre-flash, Thermal de-asphalthing dan Hydrofinishing. Proses hydrofinishing dibagi menjadi 3 produk oli yaitu Spindel Lube Fraction, High Lube Fraction, Light Lube Fraction. Sistem perpipaan SLF (Spindel Lube Fraction) yaitu sistem perpipaan dari pompa menuju kondensor, dimana kondensor tersebut berfungsi untuk mendinginkan oli. Sistem perpipaan Spindel Lube Fraction mempunyai flow rate $19841 \mathrm{~kg} / \mathrm{h}$ dengan tekanan desain 162,4 psi dan temperatur desain sebesar $375,8^{\circ} \mathrm{F}$. Sistem perpipaan ini menggunakan material A 106 Gr. C memiliki Nominal pipe Size 4 inch Sch 40.

Berat pipa dan fluida tersebut merupakan beban sustain sehingga pipa memerlukan penyangga. Penyangga memiliki banyak jenis yaitu hanger/support, restraint, dan vibration absorber [1]. Hanger/support berfungsi untuk menumpu berat dari sistem perpipaan. Restraint berfungsi untuk membatasi perpindahan disebabkan beban termal/dinamis. Vibration absorber berfungsi untuk membatasi perpindahan disebabkan getaran (angin, gempa dan aliran fluida). Penentuan allowable pipe span antara penyangga sangatlah penting karena mempertimbangkan keselamatan serta biaya (ereksi pipa) [2]. 


\section{TINJAUAN PUSTAKA}

Maksimum jarak antara penyangga/Maximum allowable pipe span yang diijinkan untuk sistem perpipaan horisontal dibatasi 3 faktor utama yaitu tegangan tekuk, defleksi vertikal, dan frekuensi alami [3].

Penyangga untuk pipa harus diberi jarak berdasarkan 3 pertimbangan: [4]

- Kemampuan penempatan penyangga di lokasi yang inginkan

- Batas jarak yang diijinkan

- Menghindari tegangan ijin yang berlebihan dan konsentrasi beban antara penyangga

Persamaan untuk perhitungan maksimum jarak penyangga yang diijinkan pipa horisontal diasumsikan menggunakan pinned/simply support yaitu: [3]

- Berdasarkan batasan tegangan

$$
L S=\frac{\sqrt{0,33 . \mathrm{ZSS}}}{\mathrm{w}}
$$

- Berdasarkan batasan defleksi

$$
L s=\frac{\sqrt[4]{\Delta \cdot E \cdot I}}{22,5 . w}
$$

Persamaan untuk perhitungan maksimum jarak penyangga pipa horisontal diasumsikan menggunakan fixed/clamp support yaitu: [3]

- Berdasarkan batasan tegangan

$$
L s=\frac{\sqrt{0,4 . \mathrm{Z} . \mathrm{S}}}{\mathrm{w}}
$$

- Berdasarkan batasan defleksi

$$
L s=\frac{\sqrt[4]{\Delta \cdot E . I}}{13,5 . \mathrm{w}}
$$

Keterangan:

$$
\text { Ls = Pipe } \operatorname{span}(\mathrm{ft})
$$

$\mathrm{S} \quad=$ Tegangan yang dijinkan (psi), lihat Tabel A1 ASME B31.3 [5]

$\mathrm{Z} \quad=$ Section Modulus pipa $\left(\right.$ in $\left.^{3}\right)$ [3]

$\mathrm{w} \quad=$ Berat total pipa per satuan panjang (lb/in)

$\Delta \quad=$ Defleksi yang diijinkan (in)

I $\quad=$ Momen inersia pada bentangan pipa $\left(\mathrm{in}^{4}\right)$ [3]

E = Modulus elastisitas pada temperatur desain (psi), lihat Tabel C6 ASME B31.3 [5]

Pemodelan tumpuan secara teoritis ada 2 jenis yaitu tumpuan sederhana (pinned support/simply support) di mana bisa rotasi sepenuhnya dan tumpuan jepit (fixed/clamp support).

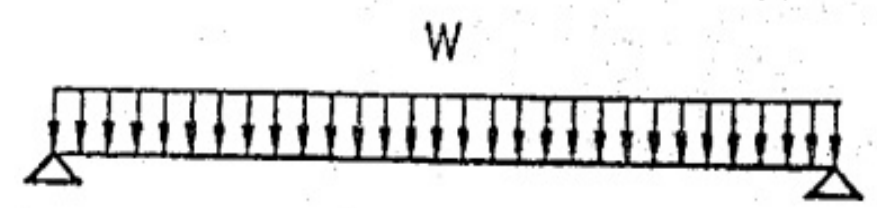

Gambar 1. Pinned/simply support

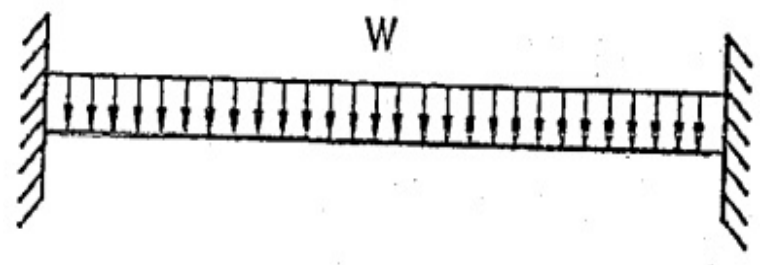

Gambar 2. Fixed/clamp support 
Kebanyakan sistem perpipaan pengilangan atau proses memiliki frekuensi alami sekitar 4 cps/cycles per second [3].

$f n=\frac{3,12}{\sqrt{\Delta}}$

Keterangan:

fn $\quad=$ frekuensi alami $(\mathrm{cps})$

Tabel 2 merupakan nilai calculation factor untuk menentukan jarak antar penyangga pipa berdasarkan frekuensi alami. Nantinya nilai calculation factor akan dikalikan dengan Ls defleksi sehingga didapatkan jarak antara penyangga pipa.

\begin{tabular}{lccccccccccc}
\multicolumn{10}{c}{ Tabel 1. Calculation factor (C) [3] } \\
$\begin{array}{l}\text { Jika } \\
\text { minimum } \\
\text { frekuensi }\end{array}$ & 3,12 & 4 & 5 & 6 & 7 & 8 & 9 & 10 & 15 & 20 \\
$\begin{array}{l}\text { yang } \\
\text { diijinkan } \\
\text { (fn) }\end{array}$ & 1,000 & 0,883 & 0,790 & 0,720 & 0,668 & 0,625 & 0,589 & 0,559 & 0,456 & 0,395 \\
$\begin{array}{l}\text { adalah C } \\
\text { dikali } \\
\text { span Ls }\end{array}$ & & & & & & & & & & & \\
\hline
\end{tabular}

Penentuan maksimum tegangan tekuk pada pipa digunakan formula sebagai berikut: [6]

$$
\mathrm{Sb}=1,2\left(\mathrm{w} \cdot \frac{\mathrm{Ls}^{\mathrm{z}}}{\mathrm{z}}\right)
$$

Penentuan maksimum defleksi pada pipa digunakan formula sebagai berikut: [6]

$$
\delta=17,1\left(w \cdot \frac{L s^{4}}{\text { E.I }}\right)
$$

Persamaan untuk perhitungan berat pipa yaitu: [3]

$$
\begin{aligned}
& \mathrm{W}_{\text {pipa }}=\frac{\pi}{4} \cdot\left(D^{2}-d^{2}\right) \cdot \rho_{\text {pipa }} \cdot L \\
& W_{\text {fluida }}=\frac{\pi}{4} \cdot\left(d^{2}\right) \cdot \rho_{\text {fluida }} \cdot L \\
& W_{\text {insulasi }}=\frac{\pi}{4} \cdot\left(D_{\text {ins }}^{2}-D^{2}\right) \cdot \rho_{\text {ins }} \cdot L \\
& W_{\text {total }}=W_{\text {pipa }}+W_{\text {fluida }}+W_{\text {insulasi }}
\end{aligned}
$$

Keterangan:

$\mathrm{W}_{\text {pipa }}=$ berat pipa $(\mathrm{lb})$

$\mathrm{W}_{\text {fluida }}=$ berat fluida $(\mathrm{lb})$

Winsulasi $=$ berat insulasi $(\mathrm{lb})$

$\mathrm{W}_{\text {total }}=$ berat total pipa $(\mathrm{lb})$

$\mathrm{L} \quad=$ panjang pipa (in)

Sehingga dapat diperoleh jumlah penyangga pipa $(\mathrm{NOS})=\frac{L}{L S}$

\section{METODE}

Penelitian ini dilaksanakan dengan metode perhitungan secara manual untuk menentukan maksimum jarak yang diijinkan antara penyangga pipa (Ls). Data yang digunakan dalam penelitian ini adalah: 
Tabel 2. Spesifikasi sistem perpipaan SLF

\begin{tabular}{|c|c|}
\hline Data & Spesifikasi \\
\hline Nominal Pipe Size (NPS) & 4 \\
\hline Schedule & 40 \\
\hline Diameter luar pipa (in) & 4,5 \\
\hline Diameter dalam pipa (in) & 4,026 \\
\hline Tebal pipa (in) & 0,237 \\
\hline Densitas pipa $\left(\mathrm{lb} / \mathrm{in}^{3}\right)$ & 0,283 \\
\hline Tebal insulasi (in) & 1,5 \\
\hline Densitas insulasi $\left(\mathrm{lb} / \mathrm{in}^{3}\right)$ & 0,0087 \\
\hline Densitas Fluida $\left(\mathrm{lb} / \mathrm{in}^{3}\right)$ & 0,032 \\
\hline Temperatur desain $(\mathrm{F})$ & 375,8 \\
\hline Tekanan desain (psi) & 162,4 \\
\hline Safety factor & 4,0 \\
\hline
\end{tabular}

Data tabel 1 digunakan untuk menghitung jarak yang diijinkan antara penyangga pipa berdasarkan batasan tegangan, defleksi, dan frekuensi alami. Setelah dihitung jarak yang diijinkan antara penyangga pipa dan diambil yang terkecil maka diketahui jumlah penyangga yang dibutuhkan [3]. Gambar 3 merupakan isometri sistem perpipaan SLF (dimensi dalam satuan $\mathrm{mm}$ ) dengan panjang total $31600 \mathrm{~mm}$ atau 103,674 ft. Pemodelan tumpuan menggunakan tumpuan sederhana (pinned support/simply support). Setelah perhitungan jumlah antara penyangga pipa didapatkan maka pada gambar 3 akan ditambahkan peletakan penyangganya.

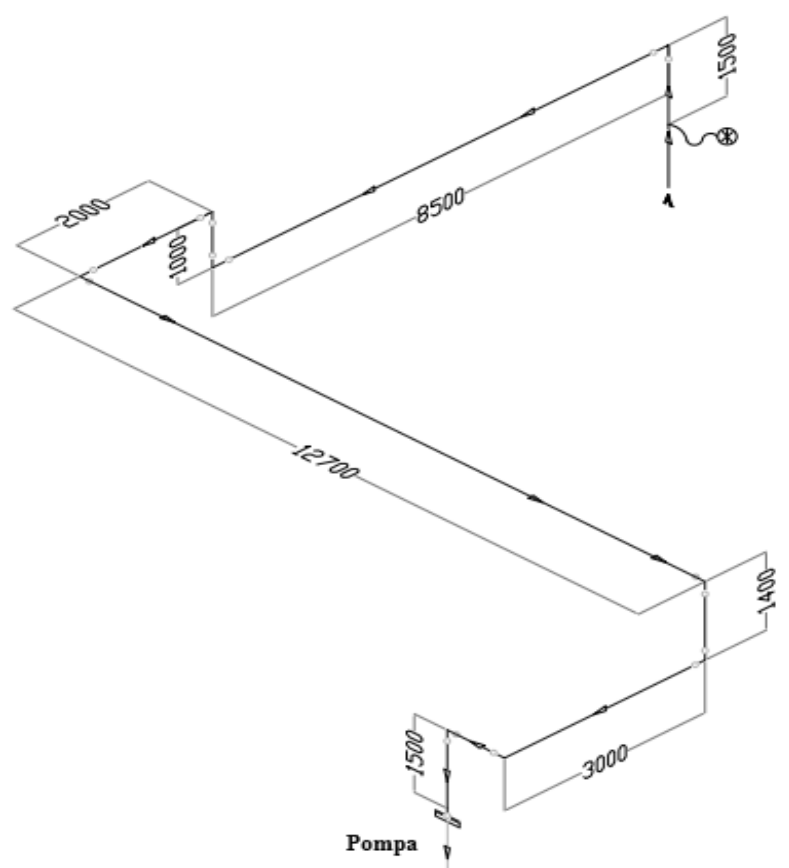

Gambar 3. Isometri Sistem perpipaan SLF

\section{HASIL DAN PEMBAHASAN}

Penentuan allowable span meliputi perhitungan berat total pipa, perhitungan maksimum jarak yang diijinkan antara penyangga pipa, dan perhitungan maksimum tegangan tekuk dan defleksi. Pertama, melakukan perhitungan berat total pipa sebagai berikut: 


$$
\begin{aligned}
\mathrm{W}_{\text {pipa }} & =\frac{\pi}{4} \cdot\left(4,5^{2}-4,026^{2}\right) \cdot 0,283 \cdot 12=10,776 \mathrm{lb} / \mathrm{ft} \\
\mathrm{W}_{\text {fluida }} & =\frac{\pi}{4} \cdot\left(4,026^{2}\right) \cdot 0,032 \cdot 12=4,884 \mathrm{lb} / \mathrm{ft} \\
\mathrm{W}_{\text {insulasi }} & =\frac{\pi}{4} \cdot\left(7,5^{2}-4,5^{2}\right) \cdot 0,0087 \cdot 12=2,951 \mathrm{lb} / \mathrm{ft} \\
\mathrm{W}_{\text {total }} & =\mathrm{W}_{\text {pipa }}+\mathrm{W}_{\text {fluida }}+\mathrm{W}_{\text {insulasi }} \\
& =10,776 \mathrm{lb} / \mathrm{ft}+4,884 \mathrm{lb} / \mathrm{ft}+2,951 \mathrm{lb} / \mathrm{ft} \\
& =18,611 \mathrm{lb} / \mathrm{ft}
\end{aligned}
$$

Sehingga berat total pipa SLF sebesar 188,611 lb/ft.

Kedua, melakukan perhitungan maksimum jarak yang diijinkan antara penyangga pipa sebagai berikut:

- Berdasarkan Batasan Defleksi

Melakukan perhitungan jarak antara penyangga pipa berdasarkan batasan defleksi:

$$
\begin{array}{ll}
\Delta & =\frac{3}{8} \mathrm{in} \\
\mathrm{E} & =27 \times 10^{6} \mathrm{psi} \\
\mathrm{I} & =7,23 \mathrm{in}^{4} \\
\mathrm{Ls}= & \frac{\sqrt[4]{\Delta \cdot \mathrm{E} . \mathrm{I}}}{22,5 . \mathrm{W}} \\
\mathrm{Ls}= & \frac{\sqrt[4]{\frac{3}{8} \cdot 27 \times 10^{6} \cdot 7,23}}{22,5.18,611} \\
\text { Ls }= & 20,44 \mathrm{ft}
\end{array}
$$

Pada perhitungan jarak antara penyangga pipa berdasarkan defleksi menunjukkan nilai 20,44 ft. Sehingga maksimum jarak antara penyangga pipa yang diijinkan berdasarkan batasan defleksi sebesar 20,44 ft.

- Berdasarkan Frekuensi Alami

Melakukan perhitungan jarak antara penyangga pipa berdasarkan frekunsi alami karena pipa terhubung dengan pompa (rotating equipment):

$$
\begin{aligned}
& \text { fn }=\frac{3,12}{\sqrt{\Delta}} \\
& \begin{aligned}
\mathrm{fn} & =\frac{3,12}{\sqrt{\frac{3}{8}}} \\
\mathrm{fn} & =14,41 \mathrm{cps} \approx 15 \mathrm{cps} \\
\mathrm{C} 3 & =0,456 \text { (berdasarkan tabel } 2) \\
\text { Ls } & =0,456 \times \text { Ls defleksi } \\
& =0,456 \times 20,44 \mathrm{ft} \\
& =9,32 \mathrm{ft}
\end{aligned}
\end{aligned}
$$

Pada pipa pulsating line (terhubung pompa) nilai frekuensi alami harus $8 \mathrm{cps}$ atau lebih [6]. Hasil perhitungan frekuensi alami menunjukkan nilai frekuensi alami di atas 8 cps yaitu $14,41 \mathrm{cps}$ sehingga masih memenuhi syarat. Sehingga berdasarkan frekuensi alami untuk maksimum jarak antar penyangga adalah $9,32 \mathrm{ft}$.

- Berdasarkan Batasan Tegangan

Melakukan perhitungan jarak antara penyangga pipa berdasarkan batasan tegangan: 


$$
\begin{aligned}
& \mathrm{Z} \quad=3,21 \mathrm{in}^{3} \\
& \mathrm{~S} \quad=22800 \mathrm{psi} \\
& \mathrm{LS}=\frac{\sqrt{0,33 . \mathrm{ZS}}}{\mathrm{w}} \\
& \mathrm{LS}=\frac{\sqrt{0,33,3,21.22800}}{18,611} \\
& \mathrm{Ls}=36,02 \mathrm{ft}
\end{aligned}
$$

Pada perhitungan jarak antara penyangga pipa berdasarkan tegangan menunjukkan nilai $36,02 \mathrm{ft}$. Sehingga maksimum jarak antara penyangga pipa yang diijinkan berdasarkan batasan tegangan sebesar $36,02 \mathrm{ft}$.

Dalam penentuan allowable span maka perlu diperhatikan tegangan tekuk dan defleksi untuk memastikan keamanan suatu sistem perpipaan. Pada tahapan ketiga ini melakukan perhitungan maksimum tegangan tekuk dan defleksi sebagai berikut:

$\mathrm{Sb}=1,2\left(\mathrm{w} \cdot \frac{\mathrm{Ls}^{2}}{\mathrm{Z}}\right)$

$\mathrm{Sb}=1,2\left(18,611 \cdot \frac{9,32^{2}}{3,21}\right)$

$\mathrm{Sb}=604,335 \mathrm{psi}$

$\mathrm{S}$ design $=\frac{\mathrm{S}}{\mathrm{FH}}$

$S$ design $=\frac{22800}{4}$

S design $=5700 \mathrm{psi}$

Pada perhitungan maksimum tegangan tekuk di atas menunjukkan nilai 604,335 psi. Nilai maksimum tegangan tekuk tersebut masih berada di bawah 5700 psi (Tegangan desain). Sehingga maksimum tegangan tekuk masih dikatakan aman. Pada perhitungan selanjutnya mempertimbangkan maksimum tegangan defleksi pada pipa.

$\delta=17,1\left(\mathrm{w} \cdot \frac{\mathrm{Ls}}{\mathrm{H} \cdot \mathrm{I}}\right)$

$\delta=17,1\left(18,611 . \frac{9,32^{4}}{27 \times 10^{6} .7,23}\right)$

$\delta=0,64$ in

Berdasarkan batasan tegangan, defleksi, dan frekuensi alami maka dipilih maksimum jarak yang diijinkan antara penyangga pipa yang paling kecil [3]. Maksimum jarak yang diijinkan antara penyanggga pipa yang dipilih yaitu $9,32 \mathrm{ft}(2840,736 \mathrm{~mm})$ dibulatkan menjadi $9,18 \mathrm{ft}(2800 \mathrm{~mm})$. Sehingga jumlah penyangga yang dibutuhkan: $\frac{103,674}{9,18} \approx 11$ buah 


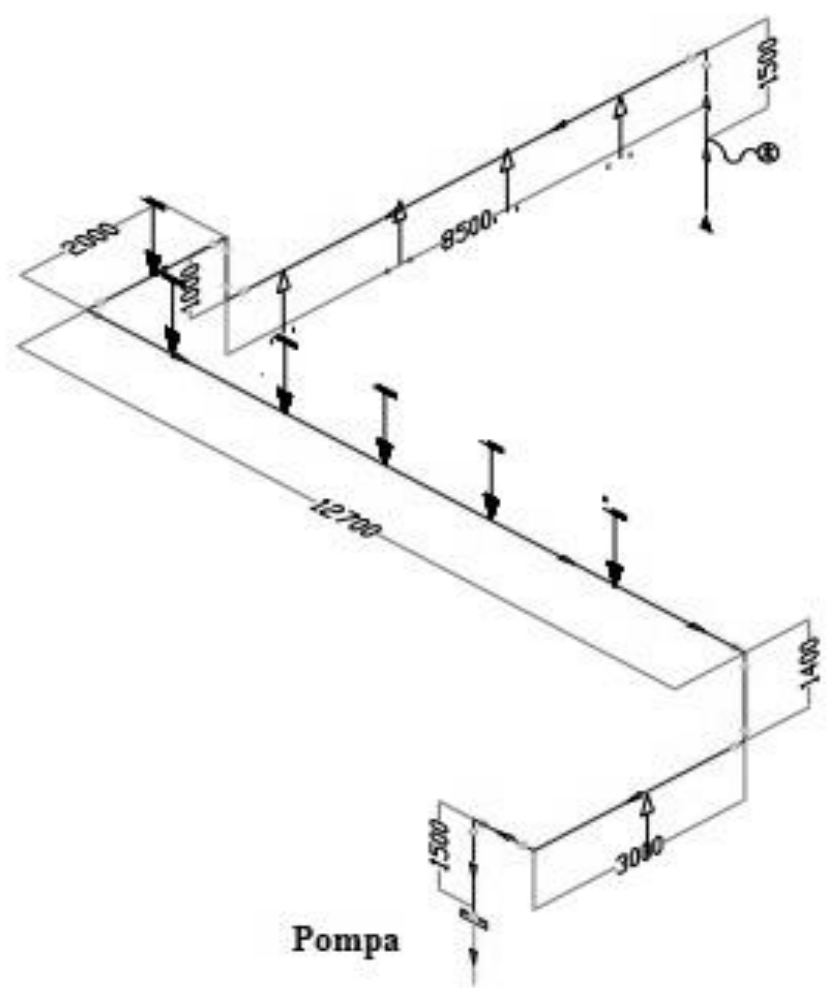

Gambar 4. Isometri Sistem perpipaan SLF menggunakan penyangga pipa

Pada Gambar 4 telah ditambahkan penyangga pipa yang sudah dihitung. Jumlah penyangga yang digunakan adalah 11 buah penyangga. Jumlah penyangga ditunjukkan pada Gambar 4. Penyangga pipa 11 buah tersebut diharapkan mampu menyangga pipa dengan aman karena pipa terhubung pompa (rotating equipment) atau pada jalur pulsating line.

\section{KESIMPULAN}

Penentuan maksimum jarak pipa yang diijinkan antar penyangga pada pipa Spindel Lube Fraction (SLF) didapatkan nilai span yang paling kecil yaitu berdasarkan frekuensi alami sebesar $9,18 \mathrm{ft}(2800 \mathrm{~mm})$. Pipa SLF memiliki nilai frekuensi alami sebesar $14,41 \mathrm{cps} \approx 15 \mathrm{cps}$. Pipa SLF berada di jalur pulsating line yang terhubung pompa sehingga nilai frekuensi alami harus lebih besar dari $8 \mathrm{cps}$ untuk mencegah adanya resonansi pada pipa. Berdasarkan maksimum tegangan tekuk masih berada di bawah batas tegangan desain sehingga dikategorikan aman. Sehingga pada pipa SLF akan terpasang jumlah penyangga sebanyak 11 buah.

\section{DAFTAR PUSTAKA}

[1] IDPipe. 2014. Indonesian Piping Knowledge. Indonesian Piping Knowledge: www.idpipe.com.

[2] Vakharia D.P., 2009. Determination of maximum span between pipe supports using maximum bending stress theory. Int Journal of Recent Trends in Engineering, Vol 1 (6): 46-49.

[3] Kannapan, S. 1986. Introduction to Pipe Stress Analysis. Canada: John Wiley \& Sons Inc

[4] Crocker, S. 1945. Piping Handbook Fourth Edition. New York: McGraw Hill Co.

[5] ASME. 2014. ASME B31.3 Piping Process. New York: ASME.

[6] Kellog, M.W. 1956. Design of Piping Systems Second Edition. New York: John Wiley \& Sons Inc. 
Halaman ini sengaja dikosongkan 